\title{
RADIATION-INDUCED DEGRADATION OF PIRIMIPHOS METHYL IN AERATED SOLUTION
}

\author{
Hendig Winarno, Agustin N. M. Bagyo, Winarti A. Lindu, \\ and Ermin K. Winarno \\ Center for R \& D of Isotopes and Radiation Technology, \\ National Nuclear Energy Agency, P.O. Box 7002 JKSKL, Jakarta 12070, Indonesia
}

\begin{abstract}
RADIATION-INDUCED DEGRADATION OF PIRIMIPHOS METHYL IN AERATED SOLUTION. Degradation of pirimiphos methyl (1) as an active ingredient in Minawet insecticide $250 \mathrm{EC}$ formulation in aqueous solution was studied. The absorbance, $\mathrm{pH}$, COD (Chemical Oxygen Demand) in aerated solution, and the analyses of degradation products at various irradiation doses with dose rate of $5 \mathrm{kGy} / \mathrm{h}$ were observed. The absorbance decreased rapidly at low doses $(\leq 10 \mathrm{kGy})$, while at high doses (>10 kGy) decreased slowly. The optimum irradiation dose for pirimiphos methyl degradation in aerated solution was found to be $15 \mathrm{kGy}$ at $\mathrm{pH}$ 3.6. At that condition, more than $99 \%$ of pirimiphos methyl has been degraded and the COD of solution decreased about $82 \%$. The analysis of irradiated samples by GC-MS and HPLC showed that 2-diethylamino-6-methyl-4-oxo-3,4-dihydropyrimidine (3) and oxalic acid were clarified as degraded products.
\end{abstract}

Keywords: pirimiphos methyl, 2-diethylamino-6-methyl-4-oxo-3,4-dihydropyrimidine, oxalic acid, degradation, COD.

\section{INTRODUCTION}

Along with rapid development of industry, the use of various organic compounds is increasing. In Indonesia, pesticide industries have developed fastly, and this fact will produce waste from the raw materials and active ingredients. If it is not managed by good handling, the waste containing active agent such as pirimiphos methyl, chlorpyriphos, carbamate will cause pollution to the environment.

Some methods for treatment of waste water such as by adsorption using activated charcoal, aeration, coagulation, or oxidation using ozone had been conducted, but so far no satisfactory results was obtained. So, more effective and efficient methods are still needed. SUN and PIGNATELLO [1] reported that $60 \%$ of 2,4-dichlorophenoxy acetic acid could be degraded by UV irradiation combined with the addition of Fenton reagent as catalyst, and the oxalic acid was clarified as an intermediate product.

The use of ionizing radiation to eliminate non biodegradable organic pollutants in raw material of drinking water and waste water had been investigated by many researchers [2-4].

Based on the previous research $[5,6]$ that fenitrothion and prothiophos insecticides could be degraded until 97\% (initial concentration was $50 \mathrm{mg} / \mathrm{L}$ ) in aerated aqueous solution using gamma radiation at the optimum 
dose $6 \mathrm{kGy}$ for fenitrothion and $8 \mathrm{kGy}$ for prothiophos, so in this research, pirimiphos methyl (1) as an active ingredient in Minawet $250 \mathrm{EC}$ formulation was choose for studying their degradation since this insecticide is used for controlling a wide range of pests of building and stored products, namely: fruits, vegetables, and other crops [7]. The chemical name of pirimiphos methyl (1) is $O$-(2-diethylamino-6-methylpyrimidin-4-yl)- $O, O$-dimethyl phosphorothioate. Its structure formula can be seen in Fig. 1.

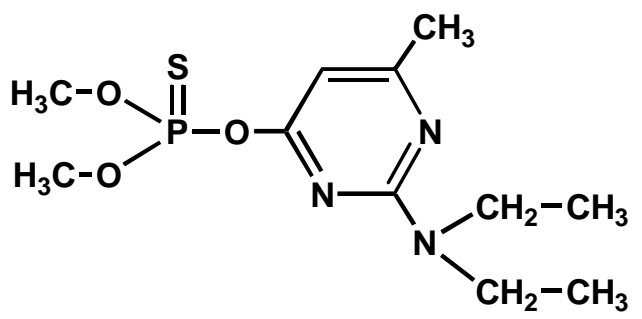

Figure 1. Chemical structure of pirimiphos methyl (1)

This research deals with the irradiation of pirimiphos methyl (1) in aqueous solution at various $\mathrm{pH}$, and analyses of the degraded product and the COD of solutions.

\section{EXPERIMENTAL}

Reagents. The Minawet 250 EC insecticide formulation containing $55 \%$ of pirimiphos methyl was used without purification. The other reagent used, namely: methanol, potassium dichromate, and iron(II) ammonium sulfate were grade reagents.

Irradiation Procedure and Analysis. Minawet 250 EC solution $(500 \mathrm{ml})$ containing $100 \mathrm{ppm}$ of pirimiphos methyl was placed in a glass vessel $(\varnothing=5.5 \mathrm{~cm}$, length $=22 \mathrm{~cm})$ and was bubbled with air during irradiation. The sample solutions were adjusted at acid conditions ( $\mathrm{pH} 3.6$ and 5.7), neutral condition ( $\mathrm{pH}$ 7), and alkaline condition ( $\mathrm{pH}$ 8.6) by added the diluted $\mathrm{HCl}$ or $\mathrm{NaOH}$. The irradiation was conducted by cobalt-60 gamma rays with doses of $5,10,15,20$, and $25 \mathrm{kGy}$ at room temperature. The dose rate $(5 \mathrm{kGy} / \mathrm{h})$ was determined using Fricke dosimeter $\left(\mathrm{G}\left[\mathrm{Fe}^{3+}\right]=15.6\right)[8]$. The absorbance of the irradiated solution was measured using a Shimadzu 160 UV-visible spectrophotometer at $\lambda=304 \mathrm{~nm}$. The pirimiphos methyl and the other compounds in Minawet 250 EC solution were analyzed using a Shimadzu LC-9A HPLC (High Performance Liquid Chromatograph) on a reverse phase adsorbent (ODS) connected with UV detector and a Finnigan MAT GC-MS (Gas Chromatography-Mass Spectrometer). The organic acids were identified by HPLC using Aminex HPX $87 \mathrm{H}$ ion exclusive column. 


\section{RESULTS AND DISCUSSION}

Decreasing the Absorbance (304 nm) of Pirimiphos Methyl Solution on Radiation at Various Dose and $\mathbf{p H}$. The pirimiphos methyl in Minawet $250 \mathrm{EC}$ formulation with concentration of $100 \mathrm{mg} / \mathrm{L}$ in aerated solution at various $\mathrm{pH}(3.6 \sim 8.6)$ was irradiated at the doses from 0 to $25 \mathrm{kGy}$ with increment of $5 \mathrm{kGy}$. The absorbance of solutions before and after irradiation which was measured at $\lambda_{\max } 304 \mathrm{~nm}$ is shown in Figure 2. Figure 2 shows that the absorbance at doses up to $10 \mathrm{kGy}$ at $\mathrm{pH} 3.6$ decrease fastly, then the decrease becomes slow at doses $>10 \mathrm{kGy}$. The decrease of absorbance at $\mathrm{pH} 3.6$ is greater than that at neutral and basic pHs. It indicated that pirimiphos methyl degraded faster on irradiation at acid medium ( $\mathrm{pH} 3.6$ ). This fact suggested that degradation at acid $\mathrm{pH}$ was greater than at basic or neutral mediums, since at acidic medium the oxidizing species $\left({ }^{\bullet} \mathrm{OH}\right.$ and $\mathrm{HO}_{2}{ }^{\bullet}$ ) increased due to the transformation reactions as described in eq. (1) (3) [9,10], while at the basic medium, the $\mathrm{O}_{2}{ }^{-\bullet}$ produced as shown at eq. (4) and (5) [10-12] is less reactive than $\mathrm{HO}_{2}{ }^{\bullet}$ and $\mathrm{OH}$ to attack pirimiphos methyl.

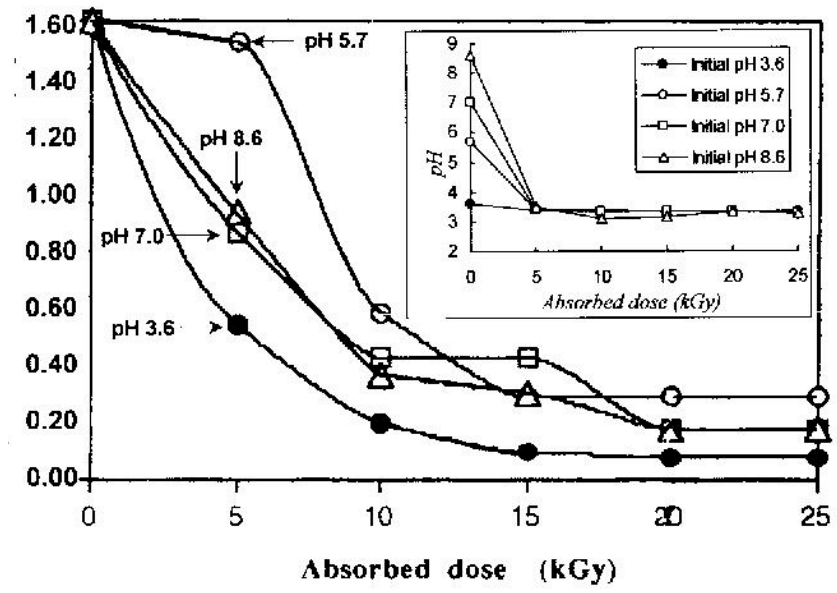

Figure 2. The effects of irradiation dose on the absorbance $(304 \mathrm{~nm})$ of the pirimiphos methyl solution at various dose and $\mathrm{pH}$

Insert: Decreasing the $\mathrm{pH}$ of pirimiphos methyl solution on radiation at various dose

Besides, ${ }^{\bullet} \mathrm{OH}$ radical and $\mathrm{H}_{2} \mathrm{O}_{2}$ molecule will be dissociated producing less reactive species as shown in reaction (6) and (7). So, it could be understood that the degradation of pirimiphos methyl by ionization radiation will be more effective at acid condition. 
Aerated acidic solution $[9,11]$ :

\begin{tabular}{|c|c|c|c|c|c|c|c|}
\hline$e_{-a q}$ & + & $\mathrm{H}^{+}$ & 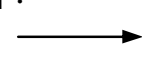 & $\mathrm{H}^{\bullet}$ & & & \\
\hline $\mathrm{H}^{\circ} \cdot$ & + & $\mathrm{H}_{2} \mathrm{O}_{2}$ & 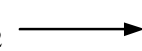 & $\mathrm{H}_{2} \mathrm{O}$ & + & $\mathrm{OH}^{\cdot}$ & \\
\hline $\mathrm{OH}^{\bullet}$ & + & $\mathrm{H}_{2} \mathrm{O}_{2}$ & & $\mathrm{H}_{2} \mathrm{O}$ & + & $\mathrm{HO}_{2}{ }^{\circ}$ & \\
\hline basic & olut & $10-12$ & & & & & \\
\hline $\mathrm{H}^{\bullet}$ & + & $\mathrm{OH}^{\circ}$ & & $\mathrm{e}_{-\mathrm{aq}}$ & + & $\mathrm{H}_{2} \mathrm{O}$ & \\
\hline $\mathrm{O}_{2}$ & + & $\mathrm{e}^{-\mathrm{aq}}$ & & $\mathrm{O}_{2}^{-\bullet}$ & & & \\
\hline $\mathrm{OH}^{\bullet}$ & & & & $\mathrm{O}^{-\bullet}$ & & $\mathrm{H}^{+}$ & \\
\hline $\mathrm{H}_{2} \mathrm{O}_{2}$ & & & & $\mathrm{HO}_{2}^{-}$ & + & $\mathrm{H}^{+}$ & \\
\hline
\end{tabular}

The $\mathrm{pH}$ change of iradiated pirimiphos methyl (initial concentration $=100 \mathrm{mg} / \mathrm{L}$ ) as Minawet $250 \mathrm{EC}$ in aerated solution at various initial pHs was also observed (Insert of Fig. 2). It was seen that $\mathrm{pH}$ of the solutions decreased fastly after irradiation at $5 \mathrm{kGy}$, but at doses $>5 \mathrm{kGy}$ the $\mathrm{pH}$ decreased slowly, or even almost no significant change. The decrease of $\mathrm{pH}$ showed that pirimiphos methyl and the other compounds in the Minawet $250 \mathrm{EC}$ aqueous solution were degraded into acidic compound.

\section{Change of Concentration as Dose Function of Pirimiphos Methyl} and Its Degradation Products. Furthermore, the irradiation of pirimiphos methyl as Minawet $250 \mathrm{EC}$ (initial concentration of pirimiphos methyl was $100 \mathrm{mg} / \mathrm{L}$ ) in aerated solution at $\mathrm{pH}$ optimum, i.e. $\mathrm{pH} 3.6$ was conducted. The concentrations of pirimiphos methyl remained and the degradation product (compound 3) is shown in Figure 3, while the COD of solution and oxalic acid produced were inserted in Fig. 3.

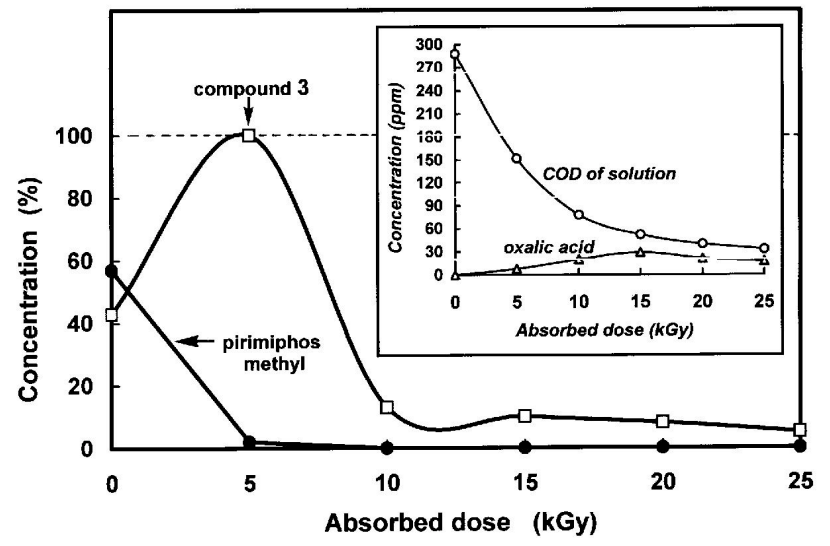

Figure 3. Effect of irradiation doses on the change of concentration of pirimiphos methyl (initial conc. $100 \mathrm{mg} / \mathrm{L}$ ) and degradation product (compound 3)

Insert: COD of the solutions and oxalic acid formed as dose function 
The concentration of compound 3 at the dose of $5 \mathrm{kGy}$ (check by HPLC on reverse phase absorbent at UV $254 \mathrm{~nm}$, retention time $=2.68 \mathrm{~min}$, inserted in Fig. 4) is highest then another dose. If the concentration of compound 3 at that dose is assumed as $100 \%$, it suggested that compound 3 has been formed (43\%) before irradiation. It was understood that concentration of pirimiphos methyl before irradiation was only $57 \%$ (checked by HPLC, the retention time $=5.83 \mathrm{~min}$ ) relative to compound 3 . The formation of compound 3 was caused by hydrolysis of pirimiphos methyl when the $\mathrm{pH}$ was adjusted to $\mathrm{pH} 3.6$ using $\mathrm{H}_{2} \mathrm{SO}_{4}$ solution. The compound 3 appeared at retention time $=2.68 \mathrm{~min}$ (inserted in Fig. 4). At the dose of 5 $\mathrm{kGy}$, the peak of compound $\mathbf{3}$ was greater then the control solution $(0 \mathrm{kGy})$, while pirimiphos methyl almost degraded completely (98\%).

At the dose of $5 \mathrm{kGy}$, the amount of $\mathrm{OH}$ radicals was not enough to attack compound 3, because the $\mathrm{OH}$ radicals will be captured by scavenger radical that may be formed from radiolysis of the other compounds in Minawet aqueous solution. Therefore the amount of $\mathrm{OH}$ radical for attacking the aromatic ring in compound 3 was not effective. At $10 \mathrm{kGy}$, the compound 3 concentration decreased sharply, then at doses higher than $10 \mathrm{kGy}$ decreased slightly.

The COD of solution decreased from $288 \mathrm{mg} / \mathrm{L}$ before irradiation to $33 \mathrm{mg} / \mathrm{L}$ after irradiation at the dose of $25 \mathrm{kGy}$. From Fig. 3, it can be seen that $15 \mathrm{kGy}$ is the optimum dose for pirimiphos methyl degradation. At this condition, the pirimiphos methyl had been degraded completely, then $92 \%$ of compound 3 was degraded, and COD of the solution decreased $82 \%$ (from 288 to $52 \mathrm{mg} / \mathrm{L}$ ). Analyses of organic acids produced from irradiated sample using HPLC on Aminex HPX $87 \mathrm{H}$ ion exclusive column at UV $210 \mathrm{~nm}$ shown that the oxalic acid was a major product. Oxalic acid concentration increased until the dose of $15 \mathrm{kGy}$, then decreased at doses $>15 \mathrm{kGy}$. It was suggested that the oxalic acid degraded moreover into smaller compounds such as $\mathrm{NH}_{3}, \mathrm{CO}_{2}$ and $\mathrm{H}_{2} \mathrm{O}$.

Confirmation of compound 3 by $\boldsymbol{G C}$ - $\boldsymbol{M S}$. The compound 3 as degradation product was assumed as 2-diethylamino-6-methyl-4-oxo-3,4dihydropyrimidine (3) as described in the following reaction :

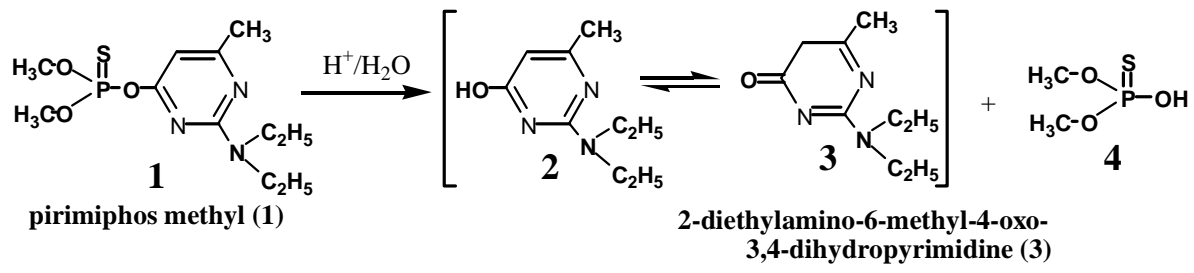

To confirm the compound 3 was 2-diethylamino-6-methyl-4-oxo-3,4dihydropy- ridine, the collected peak at retention time of $2.68 \mathrm{~min}$ from HPLC analysis (insert of Fig. 4) was injected into GC-MS on electron impact 
(EI) mode (Fig. 4). From the EI-MS spektrum, it was seen that the $\left(\mathrm{M}^{+}\right)$is 181 that was correspond to the molecular weight of 2-diethylamino-6-methyl4-oxo-3,4-dihydropyrimidine. If the $\mathrm{m} / \mathrm{z}$ were $181\left(\mathrm{M}^{+}\right), 166,152$ (base peak, $100 \%), 138,125,110,109$, so that the plausible fragmentation of compound 3 as described in Fig. 5 fitted with 2-diethylamino-6-methyl-4oxo- 3,4-dihydropyrimidine. Subsequently, it was clarified that compound 3 seem to be 2-diethylamino-6-methyl-4-oxo-3,4-dihydropyrimidine.

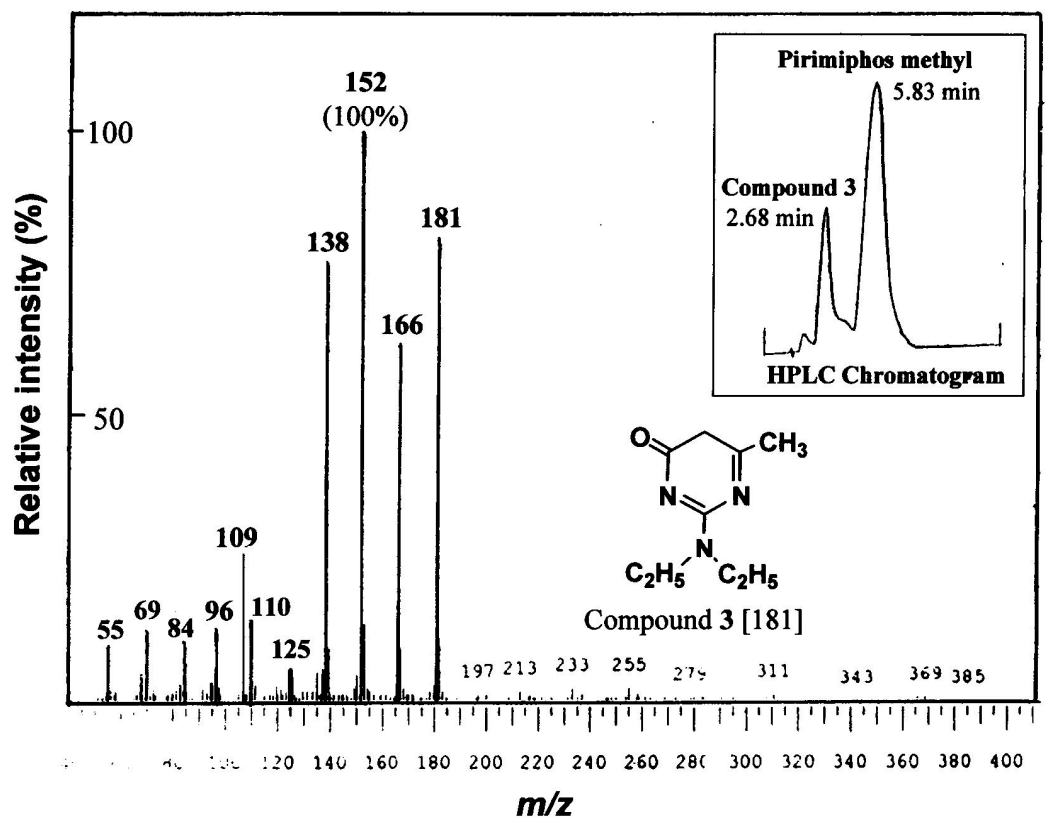

Figure 4. Electron impact-mass spectrum of 2-diethylamino-6-methyl-4oxo-3,4-dihydropyrimidine (3)

Insert: HPLC chromatogram on reverse phase adsorbent of pirimiphos methyl in acid condition (r.t. $2.68 \mathrm{~min}$ was compound 3 as degradation product). 


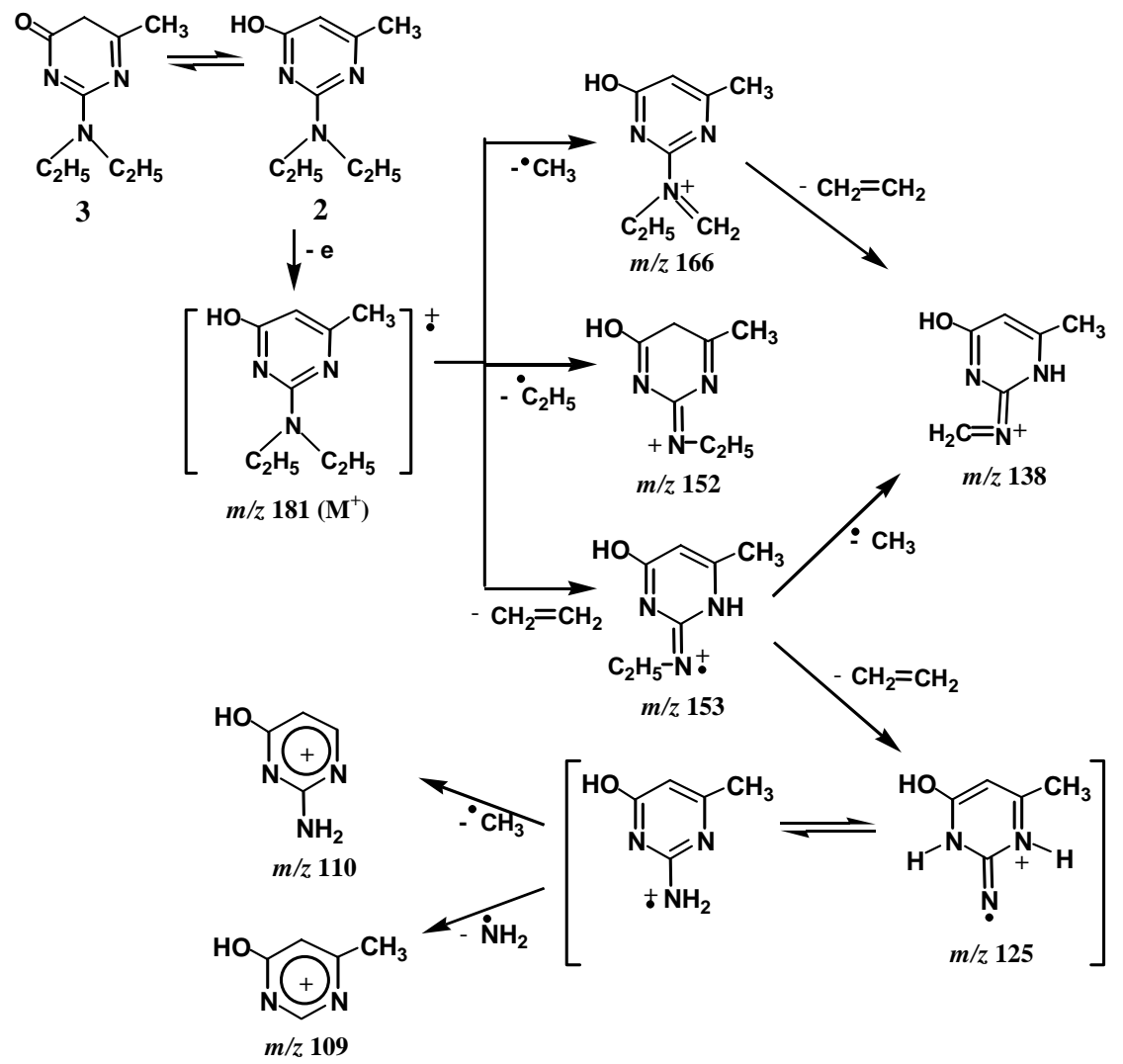

Figure 5. Plausible fragmentation of compound 3.

\section{CONCLUSION}

Gamma irradiation can degrade the compounds in Minawet 250 EC aqueous solution to acid compound. The optimum condition for degrading pirimiphos methyl and other compounds in aerated solution of Minawet $250 \mathrm{EC}$ is irradiation at the dose of $15 \mathrm{kGy}$ and $\mathrm{pH} 3.6$. At this condition, pirimiphos methyl and a hydrolytic product of pirimiphos methyl, namely 2diethylamino-6-methyl-4-oxo-3,4-dihydropyrimidine can be degraded $100 \%$ and $92 \%$, respectively, and COD of the solution decreased $82 \%$. The organic acid produced from radiolysis of this insecticide was oxalic acid. 


\section{ACKNOWLEDGEMENTS}

The authors are grateful to Mr. Syurhubel, Mrs. Christina Tri Suharni, and Mr. Armanu for their technical assistances. Thanks are also to the members of Installation of Irradiation Facility of Center for R\&D of Isotopes and Radiation Technology-NNEA.

\section{REFERENCES}

1. SUN, Y. and PIGNATELLO, J., Photochemical reactions involved in the total mineralization of 2,4-D by $\mathrm{Fe}^{3+} / \mathrm{H} 2 \mathrm{O} 2 / \mathrm{UV}$, Environ. Sci. Technol., 27 (1993) 304.

2. PROKSCH, E., GEHRINGER, P., SZINOVATS, W., and ESCHWELER, H., Radiation-induced decomposition of small amounts of trichloroethylene in drinking water, Appl. Radiat. Isot., 40 (1989) 133.

3. GETOFF, N., Radiation-induced degradation of water pollutants : State of the art, Radiat. Phys. Chem., 47 (1996) 581.

4. GETOFF, N., Advancements radiation-induced degradation of pollutants in drinking water, Appl. Radiat. Isot., 40 (1989) 585.

5. WINARNO, E. K., LINDU, W. A., ARMANU, and WINARNO, H., Degradation of fenitrothion insecticide in aqueous solution by gamma irradiation, Jurnal Nusantara Kimia, 97.1D (1997) 240-255. (In Indonesian).

6. WINARNO, E. K., LINDU, W. A., and WINARNO, H., "Radiolysis of tokuthion 500 EC insecticide in aqueous solution", (Proc. of Seminar on Appl. of Isotopes and Radiation, BATAN, Jakarta, 1996/1997), Jakarta (1997) 149-158. (In Indonesian).

7. ANONYMOUS, Farm Chemical handbook, 1996, Willoghby, Meister Pub. Co., (1996) C305.

8. SEHESTED, K., "The Fricke Dosimeter", Manual on Radiation Dosimetry (HOLM, N. W. and BERRY, R. J., Eds.), Marcel Dekker, New York (1970) 313.

9. QUINT, R. M., PARK, H. R., KRAJNIK, P., SOLAR, S., GETOFF. N., and SEHESTED, K., Gamma radiolysis and pulse radiolysis of aqueous 4-chloroanisole, Radiat. Phys. Chem., 47 (1996) 835.

10. BURTON, M. and MAGEE, J., Advances in Radiation Chemistry, Vol. 1, New York, John Wiley \& Sons Inc. (1969) 109. 
11. EL-ASSY, N. B., EL-WAKELL, E. E., and FATTAH, A. A. A., The degradation of triazo dye chlorantine fast green BLL in aqueous solutions by gamma radiation, Appl. Radiat. Isot., 42 (1991) 89.

12. SPINKS, J. W. T. and WOODS, R. J., An Introduction to Radiation Chemistry, John Wiley \& Sons Inc. (1976) 256. 